\title{
Oxidation Experiments and Kinetics Analysis of Nuclear Graphite ET-10 by Gas Analysis and Microstructure Observation
}

\author{
Yumeng Zhao ${ }^{1}$, Yujie Dong ${ }^{2} \mathbb{D}$, Yangping Zhou ${ }^{2, * \mathbb{D}}$, Zhengcao Li ${ }^{3, *}$ and Zuoyi Zhang ${ }^{2}$ \\ 1 Department of Engineering Physics, Tsinghua University, Beijing 100084, China; zhaoym_14@163.com \\ 2 Institute of Nuclear and New Energy Technology, Tsinghua University, Beijing 100084, China; \\ dongyj@mail.tsinghua.edu.cn (Y.D.); zyzhang@mail.tsinghua.edu.cn (Z.Z.) \\ 3 State Key Laboratory of New Ceramics and Fine Processing, Key Laboratory of Advanced Materials (MOE), \\ School of Materials Science and Engineering, Tsinghua University, Beijing 100084, China \\ * Correspondence: zhouyp@mail.tsinghua.edu.cn (Y.Z.); zcli@mail.tsinghua.edu.cn (Z.L.)
}

Citation: Zhao, Y.; Dong, Y.; Zhou, Y.; Li, Z.; Zhang, Z. Oxidation

Experiments and Kinetics Analysis of Nuclear Graphite ET-10 by Gas Analysis and Microstructure Observation. Energies 2021, 14, 6392. https://doi.org/10.3390/en14196392

Academic Editor: Vincenzo

Paolo Loschiavo

Received: 22 July 2021

Accepted: 1 October 2021

Published: 6 October 2021

Publisher's Note: MDPI stays neutral with regard to jurisdictional claims in published maps and institutional affiliations.

Copyright: (c) 2021 by the authors. Licensee MDPI, Basel, Switzerland. This article is an open access article distributed under the terms and conditions of the Creative Commons Attribution (CC BY) license (https:/ / creativecommons.org/licenses/by/ $4.0 /)$.

\begin{abstract}
Nuclear graphite can be used in fission and fusion systems due to its excellent nuclear performance and mechanical properties where the ability of oxidation resistance is usually concerned. Although the excellent performance of new graphite ET-10 was revealed by previous experiments regarding the accident conditions of a fission reactor, further studies are needed to oxidize the graphite under the conditions recommended by the ASTM D7542 standard. A test facility was designed and developed to oxidize the cylindrical specimen with a $10 \mathrm{~L} / \mathrm{min}$ airflow. According to oxidation rates and microstructures of specimens, the chemical kinetics-controlled regime was determined as $675-750{ }^{\circ} \mathrm{C}$, where the activation energy was obtained as $172.52 \mathrm{~kJ} / \mathrm{mol}$. The experiment results revealed the excellent ability of graphite ET-10 for oxidation resistance with lower oxidation rates and longer oxidation times compared with some mainstream graphite. The main reasons are the low contents of some impurities and the binder and the low active surface area due to the nonimpregnation baking process undertaken to produce graphite with coal tar pitch coke. It should be noted that the evolution of oxidation behavior at the bottom part of the specimen (facing the airflow) was quicker than that at the upper part of the specimen. We also suggest that the abundance of oxygen supply and the good linearity of the Arrhenius plot are prerequisites of the chemical kinetics-controlled regime rather than sufficient conditions.
\end{abstract}

Keywords: ET-10; oxidation rate; nuclear graphite; gas analysis; activation energy; SEM; microstructure

\section{Introduction}

Nuclear graphite, with excellent nuclear performance and mechanical properties, has been widely used in high-temperature gas-cooled reactors (HTRs) as the moderator, reflector, structural material and matrix material of fuel elements [1-4]. Two main generation IV reactors, the very high-temperature gas-cooled reactor (VHTR) and the molten salt-cooled reactor (MSR), also adopt graphite as moderators [5]. Moreover, some studies showed that graphite/carbon can be good materials for fusion systems [6-8].

The mechanical and thermal properties of graphite are deteriorated by its oxidation [9-12]. Therefore, many studies have been carried out to investigate the oxidation behavior of different graphite [13-27]. The American Society for Testing and Materials (ASTM) issued the ASTM D7542 standard to measure oxidation performances of carbon and graphite materials in 2009 (updated in 2015) [28]. Recently, IBIDEN Co. Ltd. developed the new isostatic molded nuclear graphite, ET-10. Previous studies on graphite ET-10 oxidized the oblate rectangular specimens with a low gas flow rate $(0.2 \mathrm{~L} / \mathrm{min})$ considering the accident conditions of HTR based on the time criterion [19], which are different from the recommended conditions by ASTM D7542. The oxidation of graphite ET-10 started 
when the temperature reaches $700{ }^{\circ} \mathrm{C}[19]$, which is higher than the predicted temperature by ASTM D7542. Studies on other graphite showed that the differences in gas flow rates and the oxidation temperatures resulted in diversified oxidation behaviors [19-21], which can be interpreted by the change of oxygen supply and the specimen's microstructure [14,29].

The above-mentioned observations call for studies to investigate the oxidation behavior of nuclear graphite ET-10 regarding the recommended conditions by ASTM D7542 and the particularities of nuclear graphite ET-10. A test facility was designed and developed to oxidize a cylindric specimen with a $10 \mathrm{~L} / \mathrm{min}$ airflow at $675-900{ }^{\circ} \mathrm{C}$. The chemical kinetics-controlled regime of nuclear graphite ET- 10 was determined at $675-750{ }^{\circ} \mathrm{C}$, where the activation energy, $172.52 \mathrm{~kJ} / \mathrm{mol}$, was obtained by investigating the oxidation rates and the microstructures of the specimens. Our results also showed that the abundance of oxygen supply and the good linearity of the Arrhenius plot are prerequisites but not sufficient conditions to determine the chemical kinetics-controlled regime.

\section{Materials and Methods}

\subsection{Graphite Specimen and Ceramic Basket}

This study employed the isostatic molded graphite ET-10, which was manufactured by IBIDEN Co. Ltd. The specimen provided by IBIDEN Co. Ltd. is a right cylinder measuring $25.4 \mathrm{~mm}$ in height and $25.4 \mathrm{~mm}$ in diameter. Graphite ET-10 has the properties of low impurities and fine grains [29].

ASTM D7542 recommended a platinum wire basket for holding the specimen during oxidation. Since a previous study showed that the obvious oxidation of graphite ET-10 will start at around $700{ }^{\circ} \mathrm{C}[19]$, we may need to oxidize the specimen at a temperature that is higher than the highest temperature recommended by ASTM D7542, $750{ }^{\circ} \mathrm{C}$. When we carried out an oxidation experiment where the specimen temperature was around $800{ }^{\circ} \mathrm{C}$, the platinum wire was oxidized and became fragile. It indicated that the platinum wire was not applicable for the oxidation of graphite ET-10. A ceramic basket was used in oxidation experiments up to $900{ }^{\circ} \mathrm{C}$ [30]. Therefore, we designed and developed a ceramic basket $\left(\mathrm{Al}_{2} \mathrm{O}_{3}\right)$ to hold the specimen in the oxidation experiment (Figure 1).

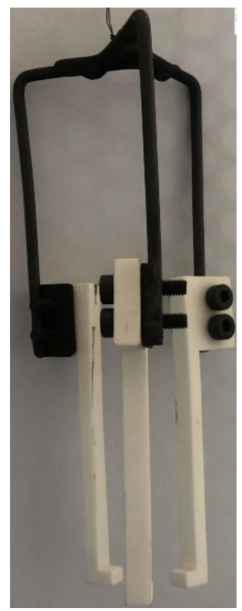

(a)

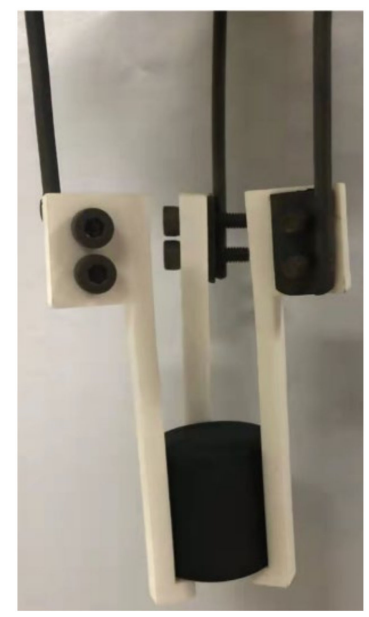

(b)

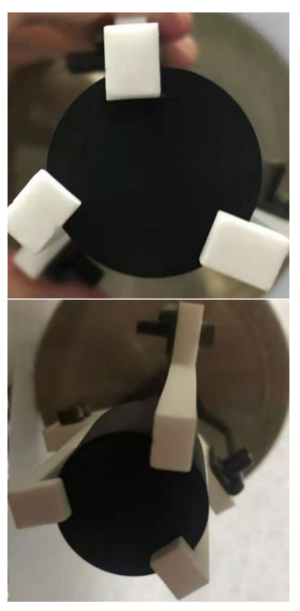

Figure 1. Ceramic basket to hold a specimen for oxidation: (a) ceramic basket; (b) ceramic basket holding a specimen.

\subsection{Test Facility and Procedures}

The test facility uses air to oxidize the graphite specimen, and its design and appearance are shown in Figure 2. It mainly includes a gas chromatograph and a vertical tube furnace. The dry air used to oxidize the specimen is obtained from atmospheric air after flowing through an air dryer and filter. The highly purified nitrogen (99.999\%) is provided by a highpressure gas tank. A mass flow meter measures the flow rate of the dry air or the highly 
purified nitrogen. The tube furnace consists of three zones heated by three independent electric heaters. The temperature of each heating zone detected by one Pt-Rh thermocouple is used to regulate the power of the related heater automatically. A ceramic specimen basket loads the specimen in the middle of a quartz tube surrounded by the heating zones. A thermocouple is inserted below the bottom of the specimen to measure the oxidation temperature. Another two thermocouples are located at the inlet and the outlet of the quartz tube to measure the temperatures of the inlet gas and the outlet gas, respectively. The gas chromatograph (GC-1100, PERSEE) measures the components of the outlet gas to obtain the oxidation rate of the specimen. Before and after oxidation, the masses of the specimen are measured by an analytical balance (ML204T/02, Mettler Toledo).

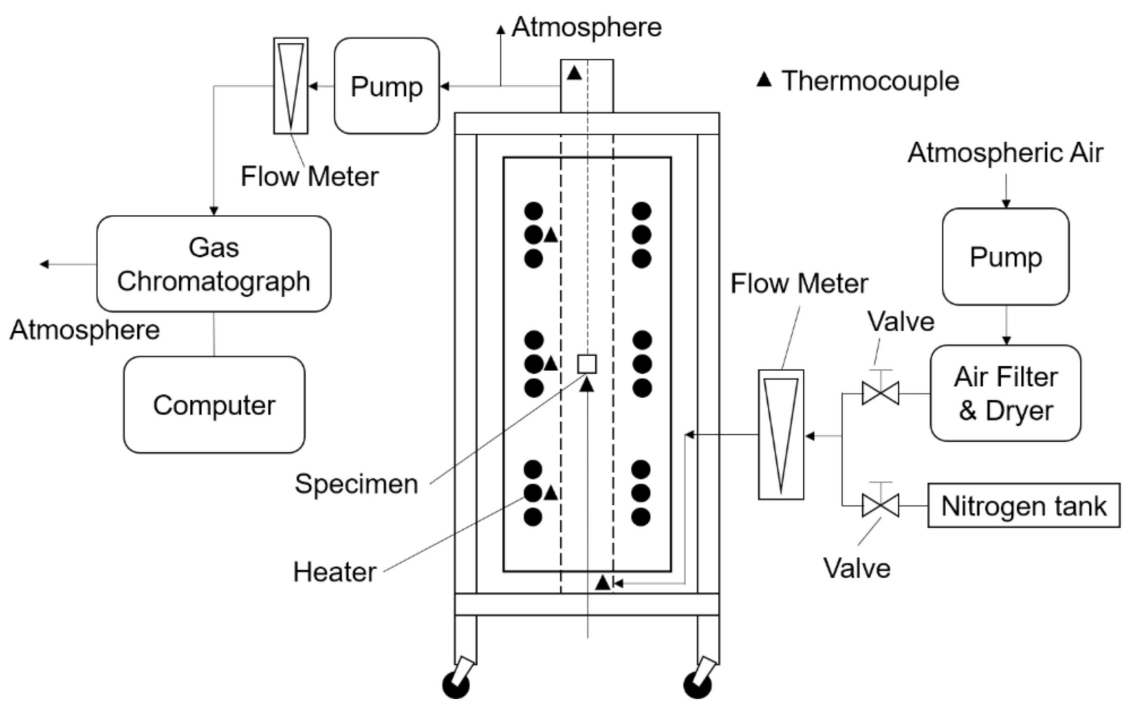

(a)

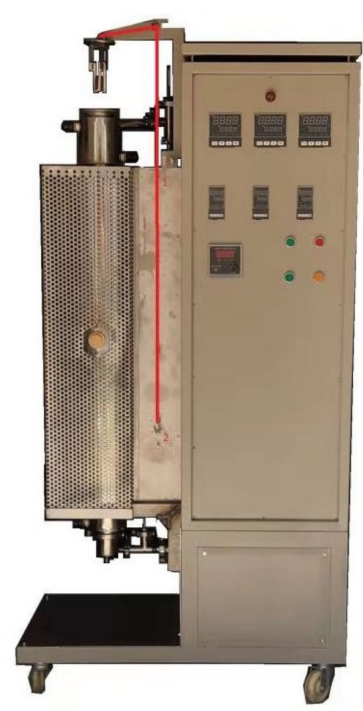

(b)

Figure 2. Test facility for graphite oxidation: (a) design of test facility; (b) main body of test facility.

The experiment procedure includes four steps. Before oxidation, nitrogen is injected into the quartz tube. Then, the test specimen is heated to a target oxidation temperature in an inert atmosphere. After that, the air is injected into the quartz tube to oxidize the graphite. Finally, the test specimen is cooled after changing to the inert atmosphere.

The oxidation temperature ranged from $675{ }^{\circ} \mathrm{C}$ to $900{ }^{\circ} \mathrm{C}$, and the flow rate of inlet gas was $10 \mathrm{~L} / \mathrm{min}$. During a test, the oxidation rate and the mass loss of the specimen were calculated according to the components of the outlet gas measured by the gas chromatograph normally every $10 \mathrm{~min}$. After an oxidation experiment was finished, the oxidation rate and the mass loss of the specimen were corrected according to the masses of the un-oxidized specimen and the oxidized specimen obtained by analytical balance. For each oxidation temperature, we carried out at least two coincident experiments.

The heat produced by the oxidation of the specimen may change the specimen's temperature during oxidation. Moreover, the heat will increase with the increase in oxidation temperature. When the oxidation experiment is carried out at a high temperature (equal to or higher than $750{ }^{\circ} \mathrm{C}$ ), the heat can raise the temperature of this specimen quickly, and a manual power regulation of the heaters may be needed. The actual oxidation temperature obtained by the thermocouple sometimes deviates from the target temperature, which will change the oxidation rate of the specimen especially after the initial stage of the oxidation experiment. Therefore, we use the average value of the specimen's temperature after the initial stage of an oxidation experiment when comparing the oxidation rates and the mass losses of the specimens.

The oxidized specimen will be processed into flakes by wire cutting. These flakes were rinsed in acetone with an ultrasonic cleaner and then dried for $2 \mathrm{~h}$ at $120^{\circ} \mathrm{C}$. Finally, 
a scanning electron microscopy (SEM, Merlin VP Compact, Carl Zeiss) was used to observe the different surfaces of the specimen.

\subsection{Numerical Methods}

Since the components of the outlet gas were measured normally every $10 \mathrm{~min}$, accordingly, we calculated the related values in different time intervals. The gas flow rate at the outlet of the quartz tube can be obtained by Equation (1) as follows:

$$
v_{o, j}=v_{i, j}\left(1+0.5 C_{C O, j}\right)
$$

where $v_{0, j}(\mathrm{~mol} / \mathrm{h})=$ the gas flow rate at the outlet of the quartz tube in the jth time interval; $v_{i, j}(\mathrm{~mol} / \mathrm{h})=$ the gas flow rate at the inlet in the jth time interval; and $C_{C O, j}=$ the mole fraction of $\mathrm{CO}$ in the outlet gas in the jth time interval.

We calculated the oxidation rate of a specimen according to Equation (2), which was normalized by the initial mass of the specimen:

$$
O R_{j}^{\prime}=\frac{\left(C_{\mathrm{CO}_{2, j}}+C_{C O, j}\right) v_{o, j} M c}{m_{0}}
$$

where $O R_{j}^{\prime}(\mathrm{g} /(\mathrm{g} \cdot \mathrm{h})$ or $(\% / \mathrm{h})=$ the oxidation rate of a specimen in the $\mathrm{jth}$ time interval; $\mathrm{C}_{\mathrm{CO}_{2}, j}=$ the mole fraction of $\mathrm{CO}_{2}$ in the outlet gas in the jth time interval; $\mathrm{Mc}(\mathrm{g} / \mathrm{mol})=$ the molar mass of carbon; and $m_{0}(\mathrm{~g})=$ the initial mass of the specimen.

Since the oxidation rate of a specimen obtained by gas analysis is usually different from its actual oxidation rate, we have to correct it with the actual mass loss of the specimen. We corrected the oxidation rate of a specimen according to Equation (3) as follows:

$$
O R_{j}=\frac{O R_{j}^{\prime}\left(m_{0}-m\right)}{m_{0} \sum_{j=1}^{n}\left(O R_{j}^{\prime} t_{j}\right)}
$$

where $O R_{j}(\mathrm{~g} /(\mathrm{g} \cdot \mathrm{h})$ or $(\% / \mathrm{h})=$ the corrected oxidation rate of a specimen in the $\mathrm{jth}$ time interval; $m(\mathrm{~g})=$ the mass of the specimen after oxidation; $n=$ the number of time intervals of an oxidation experiment; and $t_{j}(\mathrm{~h})=$ the length of the jth time interval.

The mass loss of a specimen until the kth interval used the ratio of the mass loss of the specimen to its initial mass according to Equation (4):

$$
M L_{k}=\sum_{j=1}^{k}\left(O R_{j}\left(t_{j}-t_{j-1}\right)\right)
$$

where $M L_{k}(\%)=$ the mass loss of the specimen until the kth time interval.

The chemical kinetic-controlled regime of oxidation is determined by considering the oxidation rates and the pore structures of the specimens. The average oxidation rates used by Arrhenius fitting were calculated at the range of $5-10 \%$ mass loss and were normalized to the initial mass of the specimen [28]. The activation energy and the preexponential factor (frequency factor) were determined by the linear regression of the Arrhenius formula as described by Equation (5):

$$
\ln (\overline{O R})=\ln Z-\frac{1000 E_{a}}{R T}
$$

where $\overline{O R}(\mathrm{~g} /(\mathrm{g} \cdot \mathrm{h})$ or $(\% / \mathrm{h})=$ the average value of corrected oxidation rates of a specimen at the range of $5-10 \%$ mass loss; $\mathrm{Z}=$ the pre-exponential factor of the Arrhenius formula; $E_{a}(\mathrm{~kJ} / \mathrm{mol})=$ the activation energy of air oxidation of the graphite; $R(\mathrm{~J} /(\mathrm{mol} \cdot \mathrm{K}))=$ the gas constant; and $T(\mathrm{~K})=$ oxidation temperature. 
$\overline{O R}$ was calculated according to Equation (6) as follows:

$$
\overline{\mathrm{OR}}=\frac{\sum_{j=n_{1}}^{n_{2}}\left(O R_{j} t_{j}\right)}{\sum_{j=n_{1}}^{n_{2}}\left(t_{j}\right)}
$$

where $n_{1}=$ the serial number of the last time interval when the mass loss of the specimen was less than $5 \%$ of its initial mass; and $n_{2}=$ the serial number of the first time interval when the mass loss of the specimen was more than $10 \%$ of its initial mass.

The actual oxidation temperature obtained by the thermocouple is sometimes different from the target oxidation temperature. It will cause the varieties of oxidation rate and mass loss of specimens in the oxidation experiments, especially after the initial stage. The initial stage (onset stage) was set as when the mass loss is less than $5 \%$ of the initial mass of the specimen [22]. We included the deviation of the specimen temperature after the initial stage of the oxidation experiment when discussing oxidation rates, mass losses and microstructures of the specimens in different experiments, which is calculated according to Equation (7):

$$
\Delta T=\frac{\sum_{j=n_{1}}^{n}\left(0.5\left(T_{j}+T_{j-1}\right)\left(t_{j}-t_{j-1}\right)\right)}{t_{n}-t_{n_{1}-1}}-T+273.15
$$

where $\Delta T\left({ }^{\circ} \mathrm{C}\right)=$ the deviation of the specimen's temperature after the initial stage of the oxidation experiment; and $T_{j}\left({ }^{\circ} \mathrm{C}\right)=$ the actual temperature of the specimen in the $j$ th time interval.

The ratio of oxygen supply to oxygen consumed by graphite oxidation is often considered as an indicator of whether the oxidation is in the kinetic-controlled regime [14,29]. Here, we calculated the minimum value of this ratio in an oxidation experiment obtained by Equation (8) as follows:

$$
\beta=\frac{C_{i, O_{2}} m_{0} \sum_{j=1}^{n}\left(O R_{j}^{\prime} t_{j}\right)}{\operatorname{Max}\left(C_{\mathrm{CO}_{2}, j}+0.5 C_{C O, j}\right)\left(m_{0}-m\right)}
$$

where $\beta=$ the minimum value of the ratio of oxygen supply to oxygen consumed by graphite oxidation in an oxidation experiment; and $C_{i, \mathrm{O}_{2}}=$ the mole fraction of $\mathrm{O}_{2}$ at the inlet of the quartz tube.

\subsection{Criteria to Determine Kinetics-Controlled Regime}

The oxidation reaction can usually be divided into three regimes: chemical kineticscontrolled regime, in-pore diffusion-controlled regime and boundary layer diffusioncontrolled regime [31,32].

When the oxidation of the graphite migrates from the chemical kinetics-controlled regime to the in-pore diffusion-controlled regime and the boundary layer diffusion-controlled regime with the increase in temperature, the homogeneous and deep penetrating oxidation will become uneven and surface dominated [31,32]. In the chemical kinetics-controlled regime, the active surface area (ASA) is usually determined by the initial ASA and the mass loss, which is independent of the oxidation temperature. Therefore, when the mass loss of the specimen is limited in a certain range, e.g., $5-10 \%$, the changes of the oxidation rates at different temperatures can indicate the evolution of the oxidation behavior between the three regimes $[14,29,31]$. In this manner, the variations of the oxidation rates and the microstructures of the specimens can help to observe the evolution of the oxidation behavior.

On the other hand, ASTM D7542 was established to obtain activation energy, the measure of temperature effects on the oxidation rate in the chemical kinetics-controlled regime [28]. The oxygen supply was usually sufficient as around 10 times higher than that consumed by the graphite oxidation when the oxidation was chemical kinetics-controlled [14]. Moreover, the oxidation rate is determined by the Arrhenius equation when the oxidation is in the chemical kinetics-controlled regime. Therefore, the linear regressions of the logarithms of the 
oxidation rates and the reciprocals of the oxidation temperatures should have good linearity when the oxidation is in the chemical kinetics-controlled regime. The correlation coefficient $\left(R^{2}\right)$ of the fitting shall be at least 0.985 [28].

We will discuss these four criteria to determine the chemical kinetics-controlled regime of the air oxidation of graphite ET-10: oxidation rate, microstructure, oxygen supply and linearity of Arrhenius plot.

\section{Results}

\subsection{Oxidation Rate}

Figure 3 shows the bottom and side surfaces of the unoxidized specimen and the oxidized specimens. The macro surface area of the specimen is a determinate factor of the oxidation of the specimen [28]. Although the mass losses of all oxidized specimens are close to around $10 \%$, the geometries of the specimens oxidized at $675^{\circ} \mathrm{C}$ and $750{ }^{\circ} \mathrm{C}$ were not changed indicating that the oxygen penetrates and oxidizes the porous graphite evenly and deeply. Since the inert ceramic basket only shields a small part of the bottom surface of the specimen, the decrease in the total surface of the specimen exposed to the oxygen is very small. The geometry of the specimen oxidized at $900{ }^{\circ} \mathrm{C}$ became smaller, and the quick oxidation occurred much closer to the surface of the specimen, especially at the bottom surface (see Section 3.2 for further discussion). In this situation, the influence of the ceramic basket increases a little but it is still can be ignored. The three bulges of the bottom surface of the specimen oxidized at $900{ }^{\circ} \mathrm{C}$ (Figure 3) can indicate the shielded areas of the bottom surfaces of the specimens. The decrease in the total surface due to the ceramic basket is around $0.8 \%$, and the decrease in the bottom surface is around $5 \%$ according to this figure. The decrease in oxidation rate due to the ceramic basket will increase from around $0.8 \%$ (even oxidation) to around 5\% (bottom-only oxidation) with the increase in oxidation temperature. Therefore, the ceramic basket has negligible influence on the graphite oxidation, especially when the temperature is not higher than $750{ }^{\circ} \mathrm{C}$.
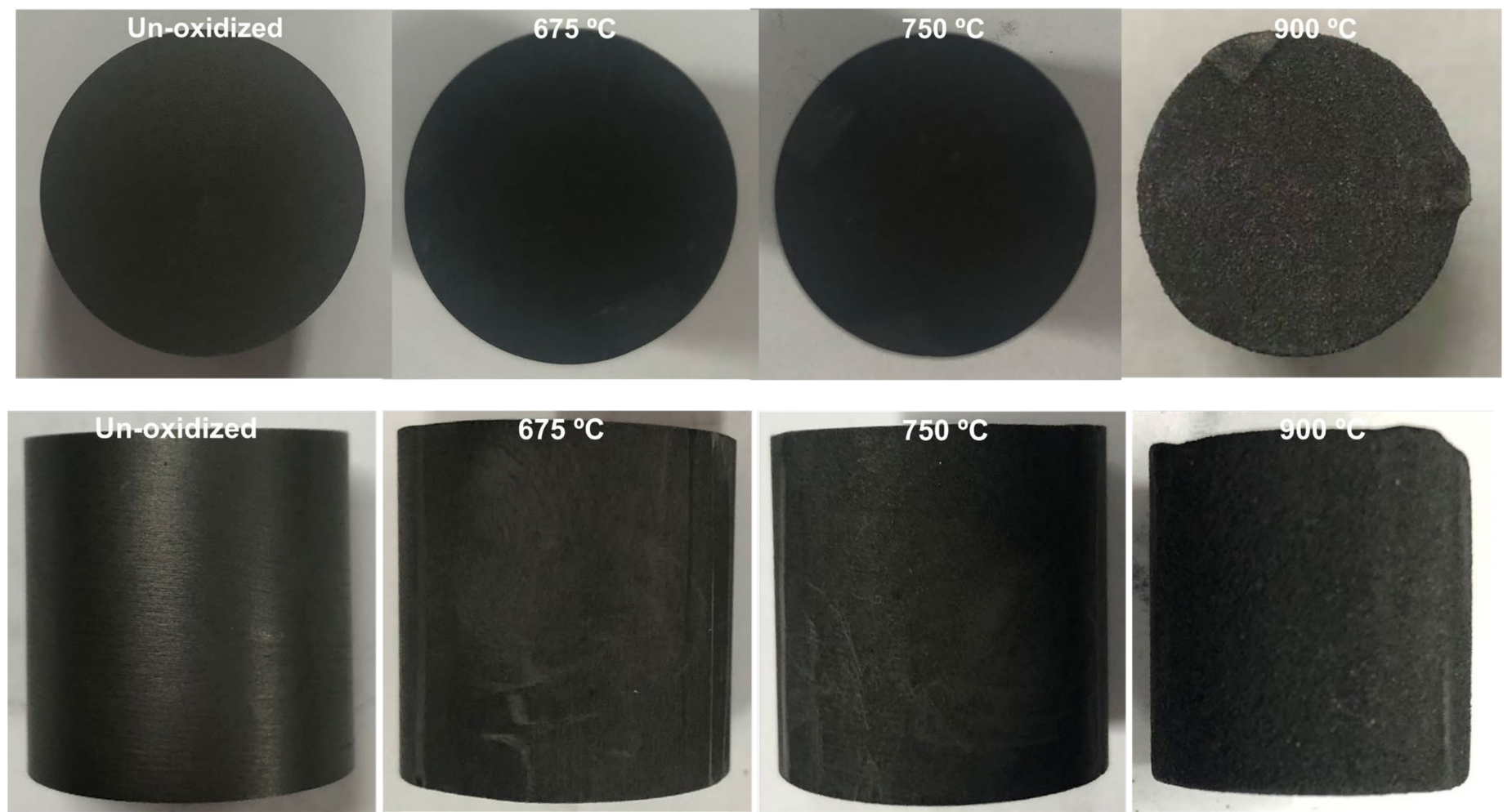

Figure 3. Bottom and side surfaces of unoxidized specimen and specimens oxidized at $675{ }^{\circ} \mathrm{C}, 750{ }^{\circ} \mathrm{C}$ and $900{ }^{\circ} \mathrm{C}$. 
Figure 4 shows the oxidation rates of graphite ET-10 at different temperatures, which are calculated according to Equation (3). The changes in the oxidation rates at the range of $5-10 \%$ mass loss indicate the transition of the oxidation among the three regimes at different temperatures. At the low-temperature regime $\left(675-750^{\circ} \mathrm{C}\right)$, the increase in oxidation rate is small with the increase in mass loss after the initial stage, corresponding to the reaction controlled by the chemical kinetics where oxygen could extend deep into the entire porous graphite with a small concentration gradient. After the temperature reaches $775{ }^{\circ} \mathrm{C}$, the oxidation rate increases obviously with the increase in mass loss after the initial stage corresponding to the in-pore diffusion regime. When the temperature is as high as $900^{\circ} \mathrm{C}$, the increase in oxidation rates is suppressed after reaching a level of mass loss, corresponding to the reaction being limited by the diffusion of oxygen and production gas near the boundary layer.

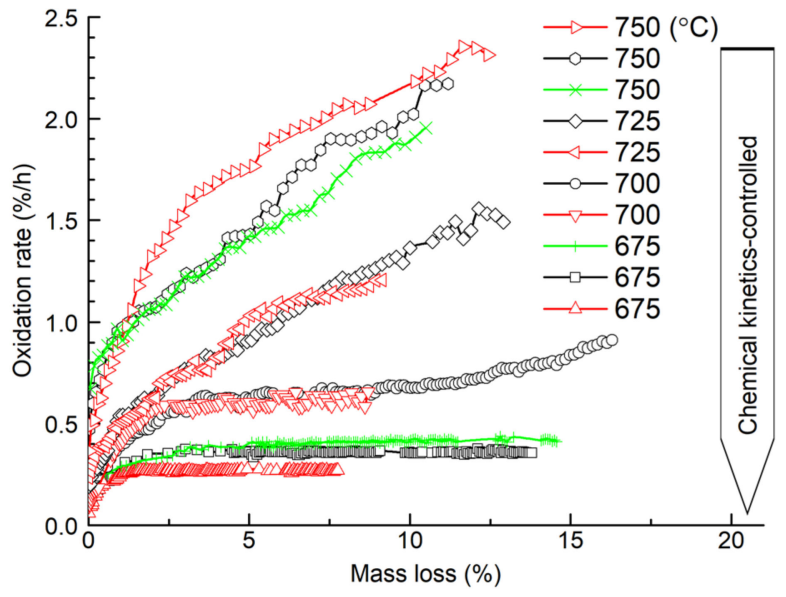

(a)

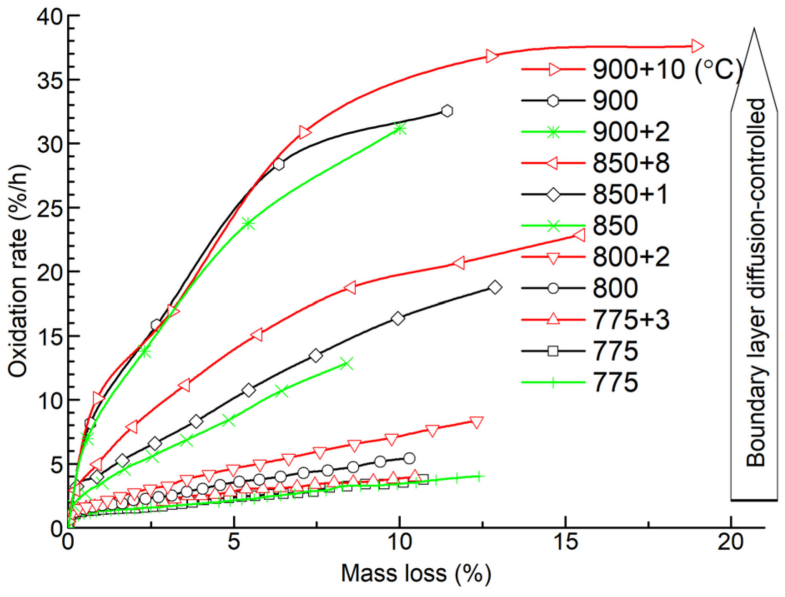

(b)

Figure 4. Oxidation rate versus mass loss of graphite ET-10 at different temperatures: (a) $675-750{ }^{\circ} \mathrm{C}$; (b) $775-900{ }^{\circ} \mathrm{C}$.

Figure 5 shows the times consumed for oxidation with the increase in mass losses of the specimens. At medium temperatures, $775-800{ }^{\circ} \mathrm{C}$, the influence of temperature deviation on the times consumed for oxidation is big because of the combination of the high oxidation rate and the long oxidation time. At low temperatures, $675-7500^{\circ} \mathrm{C}$, the oxidation rate is low. The oxidation time is short at high temperatures, $850-900{ }^{\circ} \mathrm{C}$.

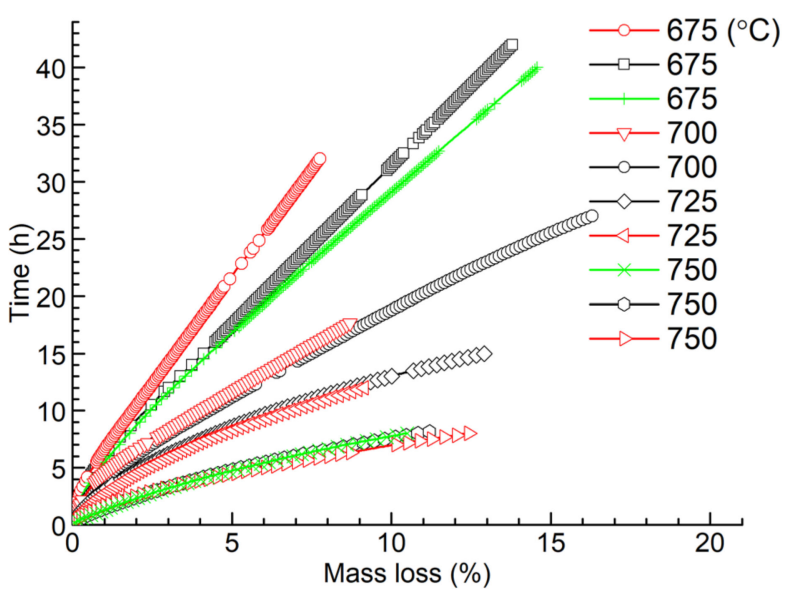

(a)

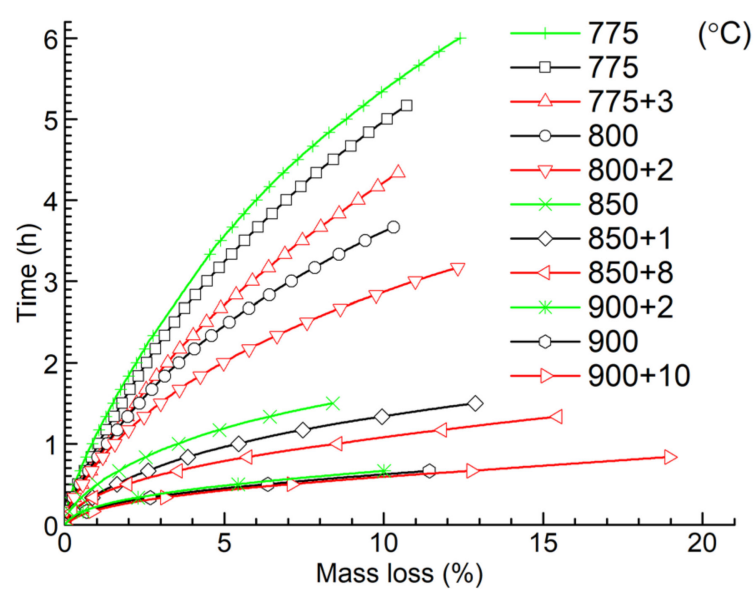

(b)

Figure 5. Oxidation time versus mass loss of graphite ET-10: (a) $675-750{ }^{\circ} \mathrm{C}$; (b) $775-900{ }^{\circ} \mathrm{C}$. 
Figure 6 compares the oxidation rates and the oxidation times of graphite ET-10 and IG-110 when the mass loss reaches $10 \%$ at different temperatures. The oxidation rates of graphite IG-110 were obtained from a previous study [16] with similar conditions. The oxidation times of graphite IG-110 were obtained from other literature [33]. The oxidation rates of graphite ET-10 are lower than those of graphite IG-110 at the same temperature. In addition, the oxidation times of graphite ET-10 are longer than those of graphite IG-110.

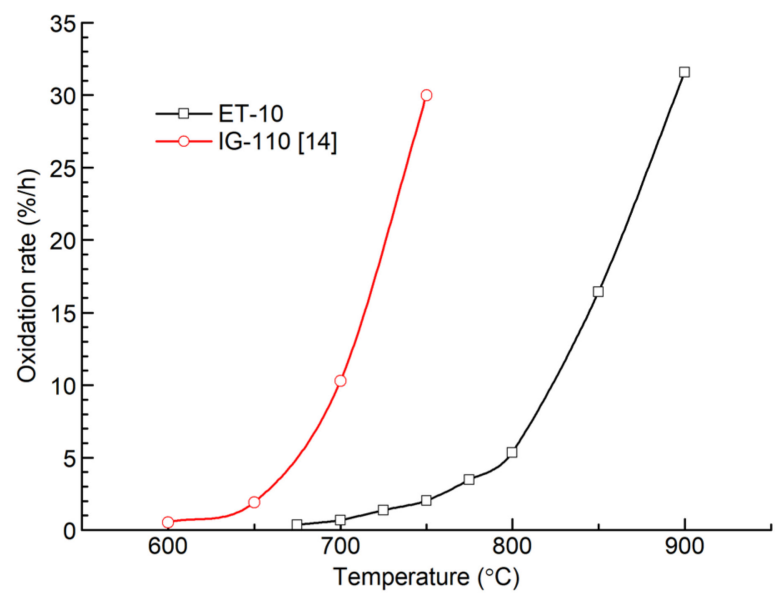

(a)

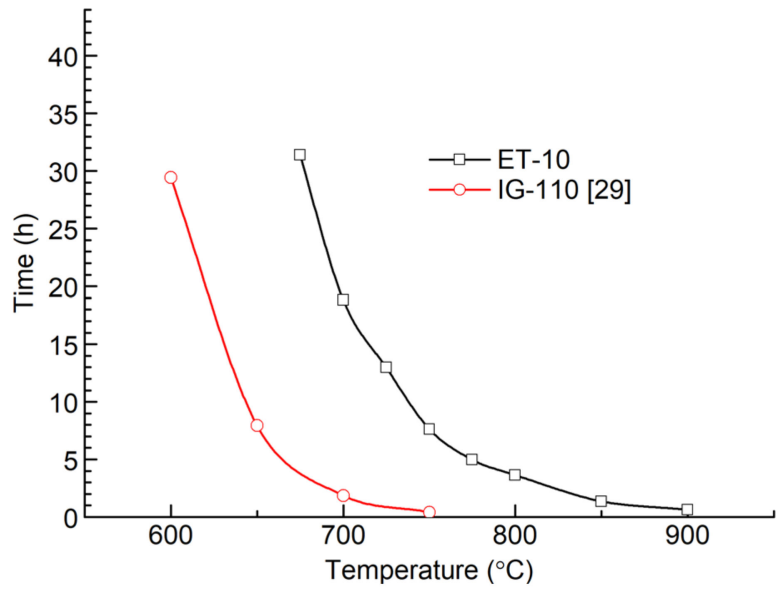

(b)

Figure 6. Oxidation rates and oxidation times of graphite ET-10 and IG-110 when mass loss reaches 10\%: (a) oxidation rates at different temperatures; and (b) times consumed at different temperatures.

\subsection{SEM Analysis}

Figure 7 shows the SEM micrographs of the specimens' bottom surfaces facing the airflow. The SEM pictures of the specimens oxidized at $725-775^{\circ} \mathrm{C}$ reveal an obvious evolution from homogeneous oxidation to inhomogeneous oxidation, indicating that oxidation moves from the kinetics-controlled regime to the in-pore diffusion-controlled regime. The obvious change stops from $800{ }^{\circ} \mathrm{C}$ to $900{ }^{\circ} \mathrm{C}$, indicating that oxidation is becoming boundary layer diffusion-controlled.

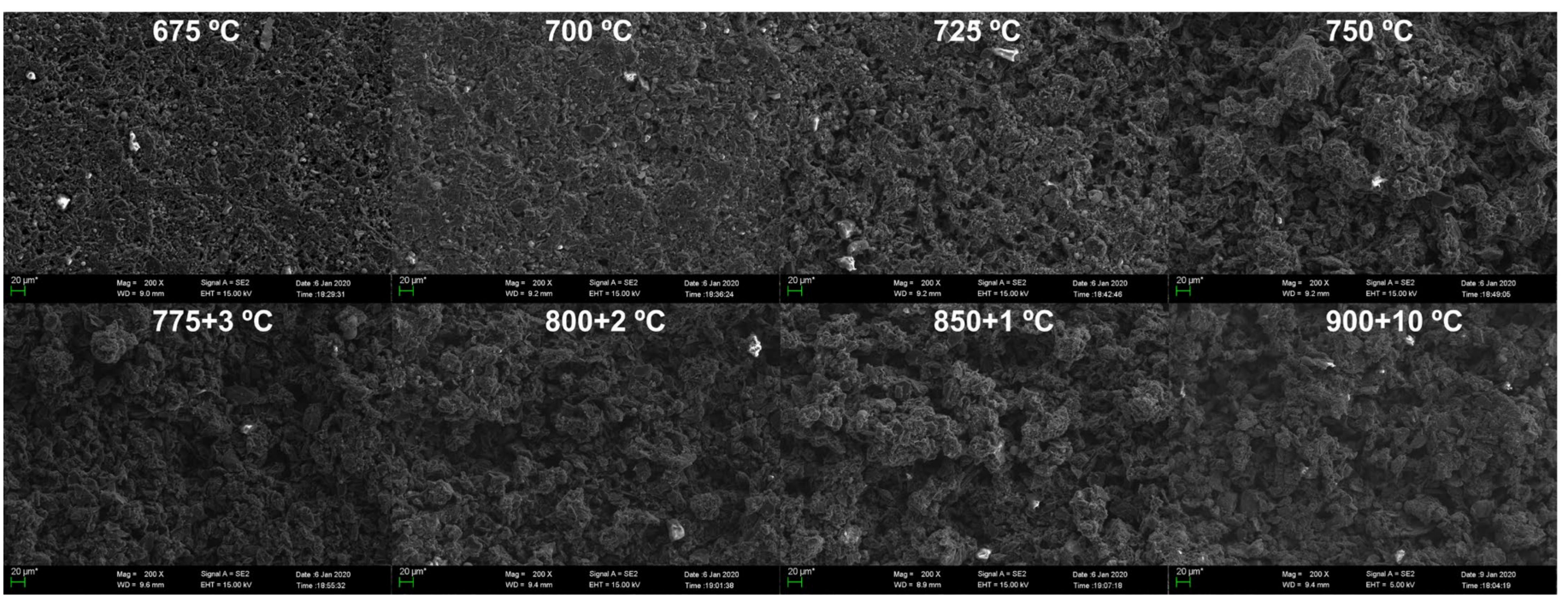

Figure 7. SEM micrographs of the bottom surfaces of oxidized graphite ET-10. 
Figure 8 shows the SEM micrographs of the specimens' upper surface. Different from Figure 7, the evolution from homogeneous oxidation to inhomogeneous oxidation starts at a higher temperature of $775{ }^{\circ} \mathrm{C}$. The changes of the upper surfaces of the specimens oxidized at $775-850{ }^{\circ} \mathrm{C}$ are similar to that of the bottom surfaces of the specimens oxidized at $725-775^{\circ} \mathrm{C}$. The obvious evolution of upper surfaces stops at $900{ }^{\circ} \mathrm{C}$.

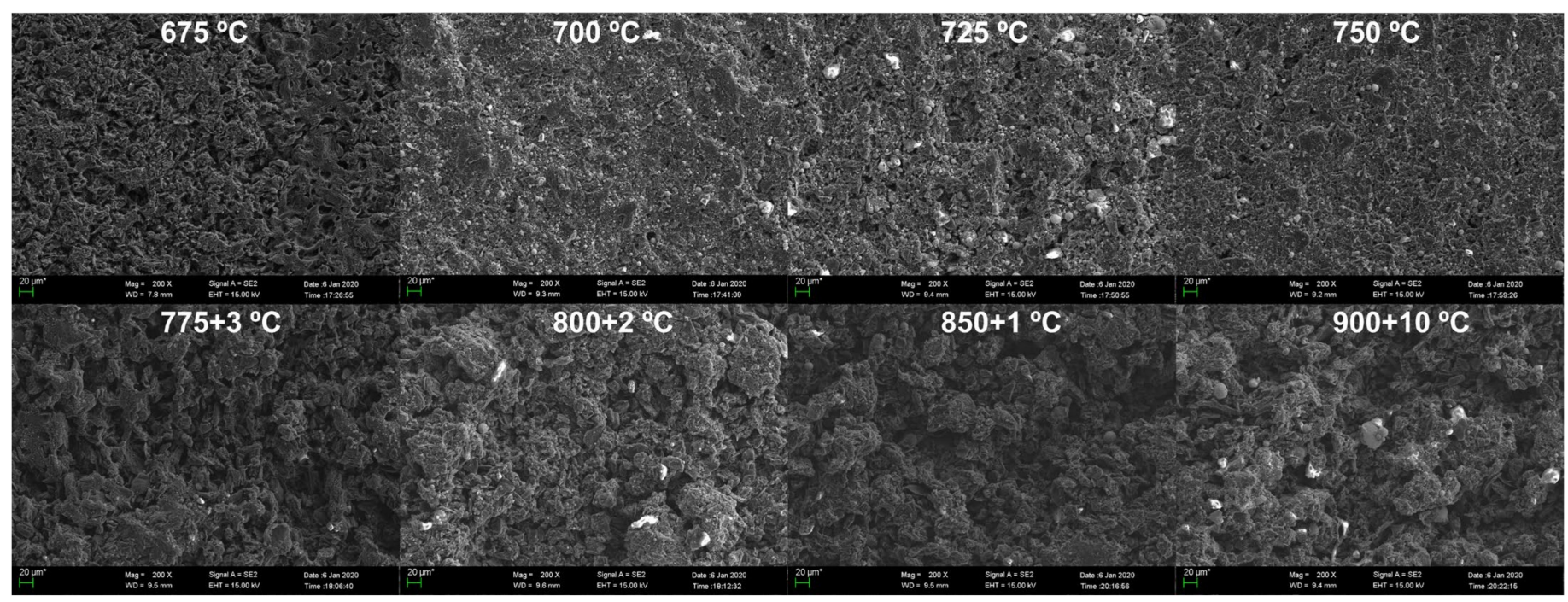

Figure 8. SEM micrographs of the upper surfaces of oxidized graphite ET-10.

The change of microstructures of the specimens also fits with the three-regime theory of graphite oxidation. At lower temperatures of $675-725^{\circ} \mathrm{C}$ in Figure 7 and $675-775{ }^{\circ} \mathrm{C}$ in Figure 8, the oxygen penetrates the porous graphite slowly and evenly in the chemical kinetics-controlled regime, and the pore structure of the surface is uniformly distributed. Then, with the increase in temperature, oxidation moves to the in-pore diffusion-controlled regime, resulting in the quicker widening and deepening of pore structure in the surface zone of the specimens. When the oxidation temperature becomes much higher at 800-900 ${ }^{\circ} \mathrm{C}$ (bottom surface) and $900{ }^{\circ} \mathrm{C}$ (upper surface), the quick oxidation occurs much closer to the surface of the graphite, quickly eliminating the pore structure in the surface zone before its further growth. At this moment, the surface is oxidized rapidly but oxygen could not further enter the inner of the graphite, indicating that oxidation is mainly boundary layer diffusion-controlled.

\subsection{Arrhenius Plot and Oxygen Supply}

We drew the Arrhenius plots of graphite ET-10 at different temperature ranges, $675-750{ }^{\circ} \mathrm{C}$, $675-850{ }^{\circ} \mathrm{C}$ and $675-900{ }^{\circ} \mathrm{C}$, in Figure $9 \mathrm{a}$. The activation energy $E_{a}$ and the pre-exponential factor (frequency factor) $Z$ were determined by the linear regression of the Arrhenius formula as Equation (5). Here, we used the related oxidation rates in the black color (Figure 4). Table 1 summarizes the values of related parameters. Even if we include the temperature of $850{ }^{\circ} \mathrm{C}$ or $900{ }^{\circ} \mathrm{C}$, the Arrhenius plot still has good linearity. In addition, the minimum value of the ratio of oxygen supply to oxygen consumed by graphite oxidation is close to 10 at 9.14 , indicating that the oxygen supply for graphite oxidation is still enough at $900{ }^{\circ} \mathrm{C}$. Therefore, the oxidation of ET-10 at $675-900{ }^{\circ} \mathrm{C}$ is kinetics-controlled according to the criteria of the linearity of the Arrhenius plot and the adequacy of oxygen supply. 


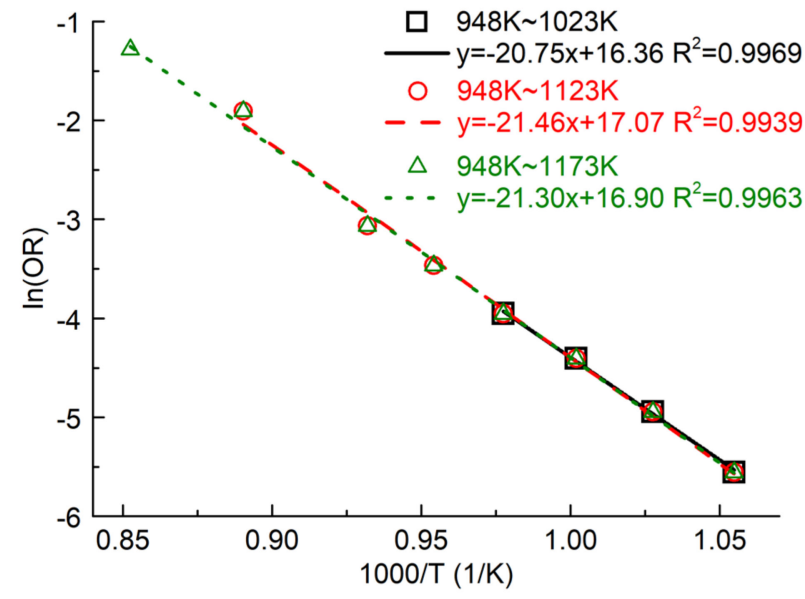

(a)

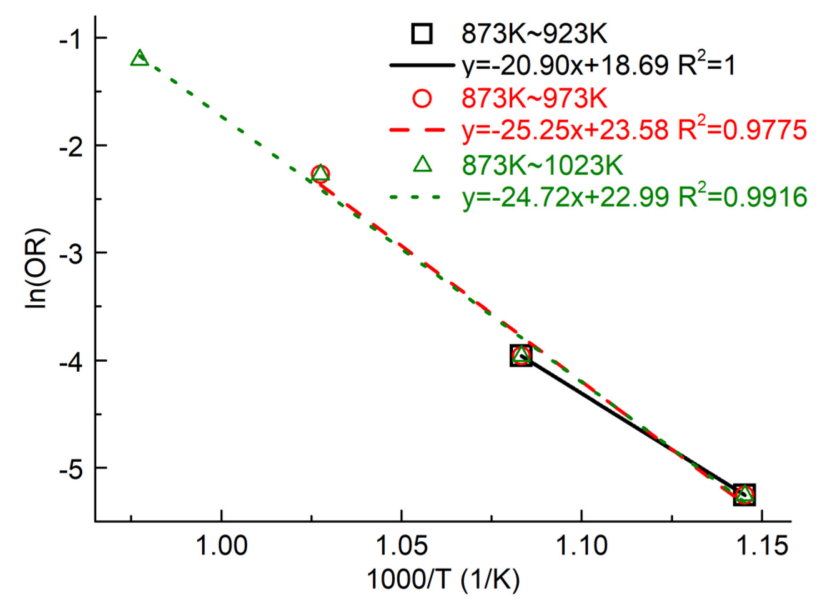

(b)

Figure 9. Arrhenius plots of graphite ET-10 and IG-110 at different temperature ranges: (a) ET-10; (b) IG-110.

Table 1. Results of linear regression of Arrhenius plots and oxygen supply in oxidation experiments of graphite ET-10.

\begin{tabular}{cccc}
\hline Parameter & Value & & \\
\hline Temperature $\left({ }^{\circ} \mathrm{C}\right)$ & $675-750$ & $675-850$ & $675-900$ \\
\hline Activation energy $(\mathrm{kJ} / \mathrm{mol})$ & 172.52 & 178.50 & 177.09 \\
\hline Adj. $\mathrm{R}^{2}$ & 0.9969 & 0.9939 & 0.9963 \\
\hline$\beta_{\text {min }}$ & 136.75 & 15.96 & 9.14 \\
\hline
\end{tabular}

Figure $9 \mathrm{~b}$ shows the Arrhenius plots of graphite IG-110 at $600-650{ }^{\circ} \mathrm{C}, 600-700{ }^{\circ} \mathrm{C}$ and $600-750{ }^{\circ} \mathrm{C}$, and the original data are obtained from another study [16]. It indicates a similar situation as that of graphite ET-10.

\subsection{Chemical Kinetics-Controlled Regime and Activation Energy}

Based on the change of oxidation rates of the specimens mentioned in Section 3.1 Oxidation Rate, the chemical kinetic-controlled regime of graphite ET-10 was determined at $675-750{ }^{\circ} \mathrm{C}$. In Section 3.2 SEM analysis, the evolution of the oxidation behavior is varied according to different surfaces of the specimens. By observing the SEM pictures of the bottom surfaces, the oxidation at $675-725^{\circ} \mathrm{C}$ is chemical kinetics-controlled. The oxidation at $675-775{ }^{\circ} \mathrm{C}$ is chemical kinetics-controlled according to the SEM pictures of the upper surfaces.

If only considering the criteria of the linearity of the Arrhenius plot and the adequacy of oxygen supply in the entire temperature range $\left(675-900{ }^{\circ} \mathrm{C}\right)$, the oxidation of graphite ET-10 is in the chemical kinetics-controlled regime. The Arrhenius plot has good linearity, and the oxygen supply is sufficient, even including the oxidation results at $900{ }^{\circ} \mathrm{C}$.

We can say that the chemical kinetics-controlled regime is $675-750{ }^{\circ} \mathrm{C}$ and the activation energy is $172.52 \mathrm{~kJ} / \mathrm{mol}$ for the air oxidation of graphite ET-10 after combining the results based on the four above-mentioned criteria.

\section{Discussion}

The chemical kinetics-controlled regime of graphite ET-10 was determined at $675-750{ }^{\circ} \mathrm{C}$ with a low value of the activation energy, $172.52 \mathrm{~kJ} / \mathrm{mol}$. Although the activation energies of present mainstream graphite are usually within the range of $180-215 \mathrm{~kJ} / \mathrm{mol}$, their chemical kinetics-controlled regimes are usually at $600-750{ }^{\circ} \mathrm{C}$ [22]. This does not indicate a low ability of oxidation resistance of graphite ET-10. The apparent activation energy of air oxidation of graphite may be quite diversified when the concerned regime changed within the range 
of $600-800{ }^{\circ} \mathrm{C}$ [32]. When the temperature range occupies the high part of $600-800{ }^{\circ} \mathrm{C}$, the value of the activation energy may be relatively small $[19,22]$.

The obvious oxidation of other graphite usually starts at around $600^{\circ} \mathrm{C}$, and it takes $7-20 \mathrm{~h}$ to reach the $10 \%$ mass loss at around $650{ }^{\circ} \mathrm{C}[14,16,22]$. The obvious oxidation of graphite ET-10 usually starts at around $675{ }^{\circ} \mathrm{C}$, and it takes around $30 \mathrm{~h}$ to reach the $10 \%$ mass loss at this temperature. Indeed, our results indicated the excellent abilities of oxidation resistance of graphite ET-10, which are also found in our previous studies with a low gas flow rate $(0.2 \mathrm{~L} / \mathrm{min})[19,29]$.

One reason for the excellent abilities of graphite ET-10 is the low contents of some impurities, e.g., vanadium and the low ASA [19]. The ASA issue may be related to the graphite filler where the oxidation of the graphite made from petroleum coke (e.g., IG-110, PCEA) was faster than that of graphite made from coal tar pitch coke (e.g., NBG-18) [16,34,35]. Another reason may be the low content of the binder due to the non-impregnation baking process for producing graphite ET-10. The binder, with more open volume porosity and more impurities than filler particles, is usually oxidized more readily than the filler particles [36].

On the other hand, the low content of the binder of graphite ET-10 and the high oxidation temperature make the oxidation more process-dependent. For the graphite with the high content of the binder, the oxidation at the initial stage where the mass loss of the specimen is less than $5 \%$ mainly oxidizes the binder, and the oxidation is then mainly determined by the mass loss of the specimen when the mass loss reaches $5-10 \%$. For the graphite ET-10, the graphite filler particles are oxidized even at the initial stage due to the low content of the binder; the oxidation, thus, is more process-dependent. It strengthens the interaction of oxidation temperature, oxidation rate and microstructure of the specimen with the increase in its mass loss. Therefore, the small deviation of oxidation temperature may be enlarged due to the enhanced interaction (Figures 4 and 5).

It should be noted that the evolution of the microstructures of the specimens varies at different parts with the increase in oxidation temperature, where the evolution of the bottom part facing the airflow is much quicker than that of the upper part (Figures 7 and 8). The change of the oxidation rate, which indicates the overall situation of the evolution of the oxidation behavior, is slower than that of the bottom part and quicker than that of the upper part (Figure 4). We can determine the chemical kinetics-controlled regime precisely by combining the changes of the microstructures and the oxidation rates of the specimens.

Graphite ET-10 has low contents of some impurities/binder and highly even microstructure, e.g., fine grain $(\sim 15 \mu \mathrm{m})$ and small pore size, etc. [29]. It is difficult for the oxygen to penetrate the inner areas of the specimen, resulting in a big difference in the oxidation of the bottom part and the upper part. The highly even microstructure also makes the change of oxidation rates of the specimens highly continuous and progressive at the concerned range of $675-900{ }^{\circ} \mathrm{C}$. Therefore, the Arrhenius plots have good linearities even including the high temperatures of $850{ }^{\circ} \mathrm{C}$ and $900^{\circ} \mathrm{C}$. Moreover, the ratio of oxygen supply to oxygen consumed by oxidation is 9.14 at $900{ }^{\circ} \mathrm{C}$, indicating that the oxygen supply is still sufficient. They indicate that the good linearities of the Arrhenius plot and the abundance of oxygen supply are prerequisites but not sufficient conditions for determining the chemical kinetics-controlled regime.

Future experiments for oxidizing other graphite, e.g., IG-110, will be conducted in this test facility to make more convincing comparisons among different graphite. A recent study indicated that the obvious oxidation of graphite IG-110 started at around $570{ }^{\circ} \mathrm{C}$ [22], which is different from the normally concerned range of $600-750^{\circ} \mathrm{C}$ and calls for further studies. In addition, we are now planning the experiments by changing airflow rates and the geometries of the specimens to discuss oxidation behavior from a broader viewpoint.

\section{Conclusions}

The oxidation behavior of nuclear graphite ET-10 was investigated by oxidizing a right cylinder specimen $(\mathrm{D}=\mathrm{H}=25.4 \mathrm{~mm})$ with a $10 \mathrm{~L} / \mathrm{min}$ airflow at $675-900{ }^{\circ} \mathrm{C}$. According to the oxidation rates and the microstructures of the specimens, the chemical kinetics- 
controlled regime was determined as $675-750{ }^{\circ} \mathrm{C}$ where the activation energy was obtained as $172.52 \mathrm{~kJ} / \mathrm{mol}$. The experiment results revealed the excellent ability of graphite ET-10 for oxidation resistance with lower oxidation rates and longer oxidation times by comparing with some mainstream graphite. The main reasons are the low contents of some impurities and the binder and the low ASA due to the adoption of a non-impregnation baking process by using coal tar pitch coke to produce graphite.

Our oxidation experiments and kinetics analysis of nuclear graphite ET-10 yielded two findings that are important for graphite oxidation. The evolution of the oxidation behavior varied at the different parts of the graphite specimen, where the bottom part facing the airflow is quicker than the upper part. We also suggest that the sufficiency of oxygen supply and the good linearity of the Arrhenius plot are prerequisites of the chemical kinetics-controlled regime rather than its sufficient conditions. These findings may call for the re-examination of the oxidation behavior of some mainstream nuclear graphites.

Author Contributions: Conceptualization, Y.Z. (Yangping Zhou) and Z.L.; methodology, Y.Z. (Yangping Zhou) and Z.L.; software, Y.Z. (Yangping Zhou); validation, Y.Z. (Yangping Zhou) and Y.Z. (Yumeng Zhao); formal analysis, Y.Z. (Yangping Zhou); investigation, Y.Z. (Yumeng Zhao); resources, Y.Z. (Yangping Zhou) and Z.L; data curation, Y.Z. (Yangping Zhou); writing—original draft preparation, Y.Z. (Yangping Zhou) and Y.Z. (Yumeng Zhao); writing-review and editing, Y.Z. (Yangping Zhou) and Y.Z. (Yumeng Zhao); visualization, Y.Z. (Yangping Zhou); supervision, Y.D.; project administration, Y.Z. (Yangping Zhou) and Z.L.; funding acquisition, Z.Z. and Y.D. All authors have read and agreed to the published version of the manuscript.

Funding: The research was funded by Chinese Major National S\&T, Grant number ZX069.

Data Availability Statement: The datasets generated during the study are available at https:// github.com/zhouyp97/OE-KA-ET-10.

Acknowledgments: The authors thank IBIDEN Co. Ltd. for providing materials used for experiments.

Conflicts of Interest: The authors declare no conflict of interest.

\section{References}

1. Shiozawa, S.; Fujikawa, S.; Iyoku, T.; Kunitomi, K.; Tachibana, Y. Overview of HTTR design features. Nucl. Eng. Des. 2004, 233, 11-21. [CrossRef]

2. Zhang, Z.; Dong, Y.; Li, F.; Zhang, Z.; Wang, H.; Huang, X.; Li, H.; Liu, B.; Wu, X.; Wang, H.; et al. The Shandong Shidao Bay 200 MWe high-temperature gas-cooled reactor pebble-bed module (HTR-PM) demonstration power plant: An engineering and technological innovation. Engineering 2016, 2, 112-118. [CrossRef]

3. Zhou, X.; Lu, Z.; Zhang, J.; Liu, B.; Zou, Y.; Tang, C.; Tang, Y. Preparation of spherical fuel elements for HTR-PM in INET. Nucl. Eng. Des. 2013, 263, 456-461.

4. Fuks, L.; Herdzik-Koniecko, I.; Kiegiel, K.; Zakrzewska-Koltuniewicz, G. Management of Radioactive Waste Containing Graphite: Overview of Methods. Energies 2020, 13, 4638. [CrossRef]

5. Marsden, B.J.; Jones, A.N.; Hall, G.N.; Treifi, P.M.; Mummery, P.M. Graphite as a core material for generation IV nuclear reactors. In Structural Materials for Generation IV Nuclear Reactors; Yvon, P., Ed.; Elsevier: Cambridge, UK, 2017; Volume 14, pp. 495-532.

6. Bowden-Reid, R.; Khachan, J. An inertial electrostatic confinement fusion system based on graphite. Phys. Plasmas 2021, 28, 042703. [CrossRef]

7. Tanabe, T. Revisiting carbon materials as plasma-facing material of a fusion reactor. Plasma Phys. Rep. 2019, 45, 300-314. [CrossRef]

8. Goriaev, A.; Wauters, T.; Brakel, R.; Brezinsek, S.; Dinklage, A.; Fellinger, J.; Grote, H.; Moseev, D.; Sereda, S.; Volzke, O. Wall conditioning at the Wendelstein 7-X stellarator operating with a graphite divertor. Phys. Scr. 2020, T171, 014063. [CrossRef]

9. Berre, C.; Fok, S.L.; Marsden, B.J.; Babout, L.; Hodgkins, A.; Marrow, T.J.; Mummery, P.M. Numerical modelling of the effects of porosity changes on the mechanical properties of nuclear graphite. J. Nucl. Mater. 2006, 352, 1-5. [CrossRef]

10. Kurumada, A.; Oku, T.; Harada, K.; Kawamata, K.; Sato, S.; Hiraoda, T.; McEnaney, B. Effects of burn-off on thermal shock resistances of nuclear carbon materials. Carbon 2014, 35, 1157-1165. [CrossRef]

11. Lim, Y.S.; Chi, S.H.; Cho, K.Y. Change of properties after oxidation of IG-11 graphite by air and $\mathrm{CO}_{2}$ gas. J. Nucl. Mater. 2008, 374 , 123-128. [CrossRef]

12. Yang, X.; Wang, X.; Tsang, D.K.L. The effect of thermal oxidation on the coefficient of thermal expansion of nuclear graphite. J. Mater. Sci. 2020, 55, 7805-7815. [CrossRef]

13. Kim, E.S.; NO, H.C. Experimental study on the oxidation of nuclear graphite and development of an oxidation model. J. Nucl. Mater. 2006, 349, 182-194. [CrossRef] 
14. Contescu, C.I.; Azad, S.; Miller, D.; Lance, M.J.; Baker, F.S.; Burchell, T.D. Practical aspects for characterizing air oxidation of graphite. J. Nucl. Mater. 2008, 381, 15-24. [CrossRef]

15. Choi, W.K.; Kim, B.J.; Kim, E.S.; Chi, S.H.; Park, S.J. Oxidation behavior of IG and NBG nuclear graphites. Nucl. Eng. Des. 2011, 241, 82-87. [CrossRef]

16. Contescu, C.I.; Guldan, T.; Wang, P.; Burchell, T.D. The effect of microstructure on air oxidation resistance of nuclear graphite. Carbon 2012, 50, 3354-3366. [CrossRef]

17. Zhou, X.; Lu, Z.; Li, X.; Zhang, J.; Liu, B.; Tang, Y. The oxidation behavior of a3-3 matrix graphite. New Carbon Mater. 2016, 31, 182-187. [CrossRef]

18. Sun, X.; Dong, Y.; Zhou, Y.; Li, Z.; Shi, L.; Sun, Y.; Zhang, Z. Effects of reaction temperature and inlet oxidizing gas flow rate on IG-110 graphite oxidation used in HTR-PM. J. Nucl. Sci. Technol. 2017, 54, 196-204. [CrossRef]

19. Yan, R.; Dong, Y.; Zhou, Y.; Sun, X.; Li, Z. Investigation of oxidation behaviors of nuclear graphite being developed and IG-110 based on gas analysis. J. Nucl. Sci. Technol. 2017, 54, 1168-1177. [CrossRef]

20. Chi, S.H.; Kim, G.C. Effects of air flow rate on the oxidation of NBG-18 and NBG-25 nuclear graphite. J. Nucl. Mater. 2017, 491, 37-42. [CrossRef]

21. Lee, J.J.; Ghosh, T.K.; Loyalka, S.K. Comparison of NBG-18, NBG-17, IG-110 and IG-11 oxidation kinetics in air. J. Nucl. Mater. 2018, 500, 64-71. [CrossRef]

22. Smith, R.E.; Kane, J.J.; Windes, W.E. Determining the acute oxidation behavior of several nuclear graphite grades. J. Nucl. Mater. 2021, 545, 152648. [CrossRef]

23. Rodriguez, D.J.; Lau, C.Y.; Long, B.A.; Tang, S.A.; Friese, A.M.; Anderson, S.L. $\mathrm{O}_{2}$-oxidation of individual graphite and graphene nanoparticles in the 1200-2200 K range: Particle-to-particle variations and the evolution of the reaction rates and optical properties. Carbon 2021, 173, 286-300. [CrossRef]

24. Bratten, A.; Duan, J.; Hoffman, A.; Wen, H.; He, X.; Stempien, J.D. Effects of microstructure on the oxidation behavior of A3 matrix-grade graphite. J. Am. Ceram. Soc. 2021, 104, 584-592. [CrossRef]

25. Lu, W.; Li, X.; Wu, X.; Sun, L.; Li, Z. Investigation on the oxidation behavior and multi-step reaction mechanism of nuclear graphite SNG742. J. Nucl. Sci. Technol. 2020, 57, 263-275. [CrossRef]

26. Li, C.; Chen, X.; Shen, L.; Bao, N. Revisiting the oxidation of graphite: Reaction mechanism, chemical stability, and structure self-regulation. ACS Omega 2020, 5, 3397-3404. [CrossRef] [PubMed]

27. Kane, J.J.; Matthews, A.C.; Swank, W.D.; Windes, W.E. Effects of air oxidation on the evolution of surface area within nuclear graphite and the contribution of macropores. Carbon 2020, 166, 291-306. [CrossRef]

28. ASTM. Standard Test Method for Air Oxidation of Carbon and Graphite in The Kinetic Regime; ASTM D7542-15; ASTM: West Conshohocken, PA, USA, 2015.

29. Zhou, Y.; Dong, Y.; Yin, H.; Li, Z.; Yan, R.; Li, D.; Gu, Z.; Sun, X.; Shi, L.; Zhang, Z. Characterizing thermal-oxidation behaviors of nuclear graphite by combining $\mathrm{O}_{2}$ supply and micro surface area of graphite. Sci. Rep. 2018, 8, 13400. [CrossRef] [PubMed]

30. Wang, M.; Xu, F.; Sun, H.; Liu, Q.; Artyushkova, K.; Stach, E.A.; Xie, J. Nanoscale graphite-supported Pt catalysts for oxygen reduction reactions in fuel cells. Electrochim. Acta 2011, 56, 2566-2573. [CrossRef]

31. El-Genk, M.S.; Tournier, J.M.P. Development and validation of a model for the chemical kinetics of graphite oxidation. J. Nucl. Mater. 2011, 411, 193-207. [CrossRef]

32. Kane, J.J.; Contescu, C.I.; Smith, R.E.; Strydom, G.; Windes, W.E. Understanding the reaction of nuclear graphite with molecular oxygen: Kinetics, transport, and structural evolution. J. Nucl. Mater. 2017, 493, 343-367. [CrossRef]

33. Wang, P.; Contescu, C.I.; Yu, S.; Burchell, T.D. Pore structure development in oxidized IG-110 nuclear graphite. J. Nucl. Mater. 2012, 430, 229-238. [CrossRef]

34. Chi, S.H.; Kim, G.C. Comparison of the oxidation rate and degree of graphitization of selected IG and NBG nuclear graphite grades. J. Nucl. Mater. 2008, 381, 9-14. [CrossRef]

35. El-Genk, M.S.; Tournier, J.M.P. Comparison of oxidation model predictions with gasification data of IG-110, IG-430 and NBG-25 nuclear graphite. J. Nucl. Mater. 2012, 420, 141-158. [CrossRef]

36. Kim, E.S.; No, H.C.; Kim, B.J.; Oh, C.H. Estimation of graphite density and mechanical strength variation of VHTR during air-ingress accident. Nucl. Eng. Des. 2008, 238, 837-847. [CrossRef] 